\title{
ESTRUTURA DO COMPONENTE ARBÓREO DE FLORESTA ESTACIONAL SEMIDECidual Montana SECUndáRia no Alto Rio Doce, Minas Gerais, Brasil
}

\author{
Renata de Melo Ferreira Lopes ${ }^{1,2}$, Glauco Santos França ${ }^{1}$, \\ Fernanda Raggi Grossi Silva ${ }^{1}$, Tereza Cristina Souza Sposito ${ }^{1}$ \\ \& João Renato Stehmann ${ }^{1}$
}

\begin{abstract}
Resumo
(Estrutura do componente arbóreo de floresta estacional semidecidual montana secundária no Alto Rio Doce, Minas Gerais, Brasil) A Estação de Pesquisa e Desenvolvimento Ambiental de Peti, um mosaico sucessional, localizase na região mineradora do Alto Rio Doce, bacia do rio Santa Bárbara. Os objetivos deste estudo foram determinar a estrutura fitossociológica de cinco áreas de floresta em diferentes estádios sucessionais e avaliar relações entre vegetação e solo. Em cada área foram amostrados 48 pontos-quadrantes e medidas as alturas e circunferências $(\geq 15 \mathrm{~cm}$ ) dos troncos das árvores. No total, foram identificadas 45 famílias, 116 gêneros e 191 espécies. As famílias com maior número de espécies foram Fabaceae, Myrtaceae, Lauraceae, Melastomataceae, Euphorbiaceae, Rubiaceae. Pogonophora schomburgkiana, Cupania ludowigii, Astronium fraxinifolium e Mabea fistulifera foram espécies de maior valor de importância. A altura média dos indivíduos variou, entre as áreas, de 7,1 $\pm 2,1$ a 9,2 $\pm 3,4$ m e o diâmetro médio de 8,9 $\pm 5,1$ a 12,1 $\pm 7,1 \mathrm{~cm}$. Duas áreas apresentaram constituição florística diferentes, de acordo com o resultado da análise de similaridade. O índice de diversidade de Shannon para espécies foi 4,58 nats/indivíduo, o que indica alta diversidade, resultante da presença de mosaico sucessional. A área que sofreu corte seletivo apresentou maior riqueza florística em comparação as demais áreas estudadas, estando todas sobre solos pobres em nutrientes e com altos níveis de alumínio.
\end{abstract}

Palavras-chave: fitossociologia, regeneração, sucessão vegetal, rio Santa Bárbara.

\section{Abstract}

(Arboreal component structure of a Seasonal Secondary Semidecidual Montane Forest in the Upper Doce River, Minas Gerais, Brazil) The Estação de Pesquisa e Desenvolvimento Ambiental de Peti, a successional mosaic of forests, is located in a mining region at the Upper Doce River in the municipalities of Santa Bárbara and São Gonçalo do Rio Abaixo, Minas Gerais. The aim of this study was to describe the phytosociological structure and evaluate the relationship between vegetation and soil of five forest areas in different successional stages. In each area, we sampled 48 points using the Point-centered quarter method, and measured circunference at breast height $(\mathrm{CBH} \geq 15 \mathrm{~cm})$ and heigh of trees. We registered a total of 45 families, 116 genera and 191 tree species. Families with highest number of species were Fabaceae, Myrtaceae, Lauraceae, Melastomataceae, Euphorbiaceae, Rubiaceae. Pogonophora schomburgkiana, Cupania ludowigii, Astronium fraxinifolium and Mabea fistulifera had the highest importance value index. Mean height ranged from 7.1 \pm 2.1 to $9.2 \pm 3.4 \mathrm{~m}$ and mean diameter from $8.9 \pm 5.1$ to $12.1 \pm 7.1 \mathrm{~cm}$. Two areas showed different floristic composition, according to similarity analysis. Shannon Diversity Index was 4.58 nats/individual, indicating considerable diversity, a result of the successional mosaic. The area submitted to selective cut presented highest floristic richness in comparison to the other areas analyzed, all of them occurring on poor soils with high levels of aluminum.

Key words: phytosociology, regeneration, vegetation sucession, Santa Bárbara river.

\section{INTRODUÇÃO}

O crescimento da população humana na América Tropical acelera a remoção da cobertura vegetal, ao aumentar a demanda por produtos florestais e terras novas para agricultura, pecuária, abertura de estradas e centros urbanos (Myers et al. 2000), o que comumente acarreta na substituição da cobertura contínua das florestas por remanescentes (Giraldo-Cañas 2000). Tais

Artigo recebido em 09/2007. Aceito para publicação em 10/2009.

${ }^{1}$ Universidade Federal de Minas Gerais, Depto. Biologia Vegetal, Av. Antônio Carlos 6627, Pampulha, 31270-901, Belo Horizonte, MG, Brasil.

${ }^{2}$ Autora para correspondência: renatademeloferreira@yahoo.com.br 
fragmentos ou ilhas de habitat, conforme descreve o modelo de biogeografia de ilhas (MacArthur \& Wilson 1967), encontram-se isolados entre si por uma matriz de áreas antropizadas, geralmente inóspitas à maioria das espécies que habitam o ambiente natural.

Inserida nesse contexto de degradação, encontra-se a região minerária da bacia do Rio Santa Bárbara, afluente do rio Piracicaba, principal afluente do rio Doce, MG. Em 1949, Santa Bárbara foi o principal município produtor de carvão vegetal para abastecimento das usinas siderúrgicas da região. As estradas de ferro foram também grandes consumidoras das florestas originais e capoeiras da bacia do rio Doce (Strauch 1955).

A região da bacia do Rio Doce, originalmente quase totalmente recoberta com vegetação característica de florestas semideciduais ou perenifólias pertencentes ao bioma da Floresta Atlântica, possui altíssima riqueza e diversidade biológica, além de abrigar um grande número de espécies de distribuição restrita a esse grande ecossistema (Fonseca 1997). A extensão dos remanescentes florestais da bacia do rio Doce foi estimada entre $5 \%$ a $6 \%$ de sua cobertura original, com base em dados do censo agrícola e do Instituto Estadual de Florestas de Minas Gerais (Fonseca 1985). Alguns estudos vegetacionais foram realizados na região (Bortoluzzi et al. 2004; Bovini et al. 2001; Gonçalves \& Lombardi 2004; Lombardi \& Gonçalves 2000; Lopes et al. 2002b).

A distribuição da vegetação arbórea é determinada por fatores ecológicos diversos, dentre eles diferenças na intensidade de penetração da luz solar (Souza et al. 2003), altitude (Gentry 1995) e constituição dos solos (Rodrigues et al. 2007; Torres et al. 1997; Botrel 2002). Strauch (1955) já havia registrado a baixa quantidade de nutrientes dos solos da região de mineração do Alto Rio Doce, que "pouco se prestam às atividades agrícolas, sendo a pecuária o meio de vida daqueles que não se entregaram às atividades ligadas à extração do ferro".

Tendo em vista a necessidade de levantamentos sobre composição e estrutura da vegetação arbórea de áreas em diferentes estágios de regeneração (considerando-se que apresentam diferentes padrões vegetacionais em função das diferentes idades sucessionais e composições de substrato), para subsidiar futuros projetos de restauração de áreas degradadas próximas, este estudo tem por objetivo: 1) determinar a estrutura fitossociológica de cinco áreas em diferentes estágios sucessionais de floresta estacional semidecidual montana, na Estação de Pesquisa e Desenvolvimento Ambiental de Peti-EPDA-Peti, localizada nos municípios de Santa Bárbara e São Gonçalo do Rio Abaixo, MG; 2) avaliar as relações entre a vegetação e as características físicas e químicas do solo.

\section{Material e Métodos}

O trabalho foi desenvolvido na Estação de Pesquisa e Desenvolvimento Ambiental de Peti - EPDA-Peti, localizada na região metalúrgica de Minas Gerais, na bacia do Rio Santa Bárbara, afluente da margem esquerda do rio Piracicaba, Alto Rio Doce, nos municípios de Santa Bárbara e São Gonçalo do Rio Abaixo, entre as coordenadas $43^{\circ} 20^{\prime} 51^{\prime \prime}$ e $43^{\circ} 23^{\prime} 28^{\prime \prime} \mathrm{W}$ e 1052’23” e 1954’27’'S (Fig. 1). Situa-se próxima à vertente leste da cadeia do Espinhaço, com altitudes que variam de 630 a $880 \mathrm{~m}$ (Nunes \& Pedralli 1995).

A Estação foi implementada em 1983 junto à Usina Hidrelétrica de Peti, da Companhia Energética de Minas Gerais CEMIG (CEMIG 2004), possuindo área de 1.374 hectares, sendo 605 ha de vegetação e 677 ha de reservatório. À montante do reservatório dominam monoculturas de Eucalyptus sp., áreas agrícolas e pastagens, sendo as jazidas de ferro no entorno da Estação atualmente exploradas pela mineradora Vale. O clima da EPDA-Peti, pela classificação de Köppen, é do tipo $\mathrm{Cwb}$ - tropical de altitude, com verões frescos e estação seca bem definida, sendo os meses de outubro a março úmidos e os de maio a setembro, relativamente secos (Antunes 1986), com pluviosidade média anual entre 1.110 e 1.700 mm (1997-2005) (ANA 2008). 


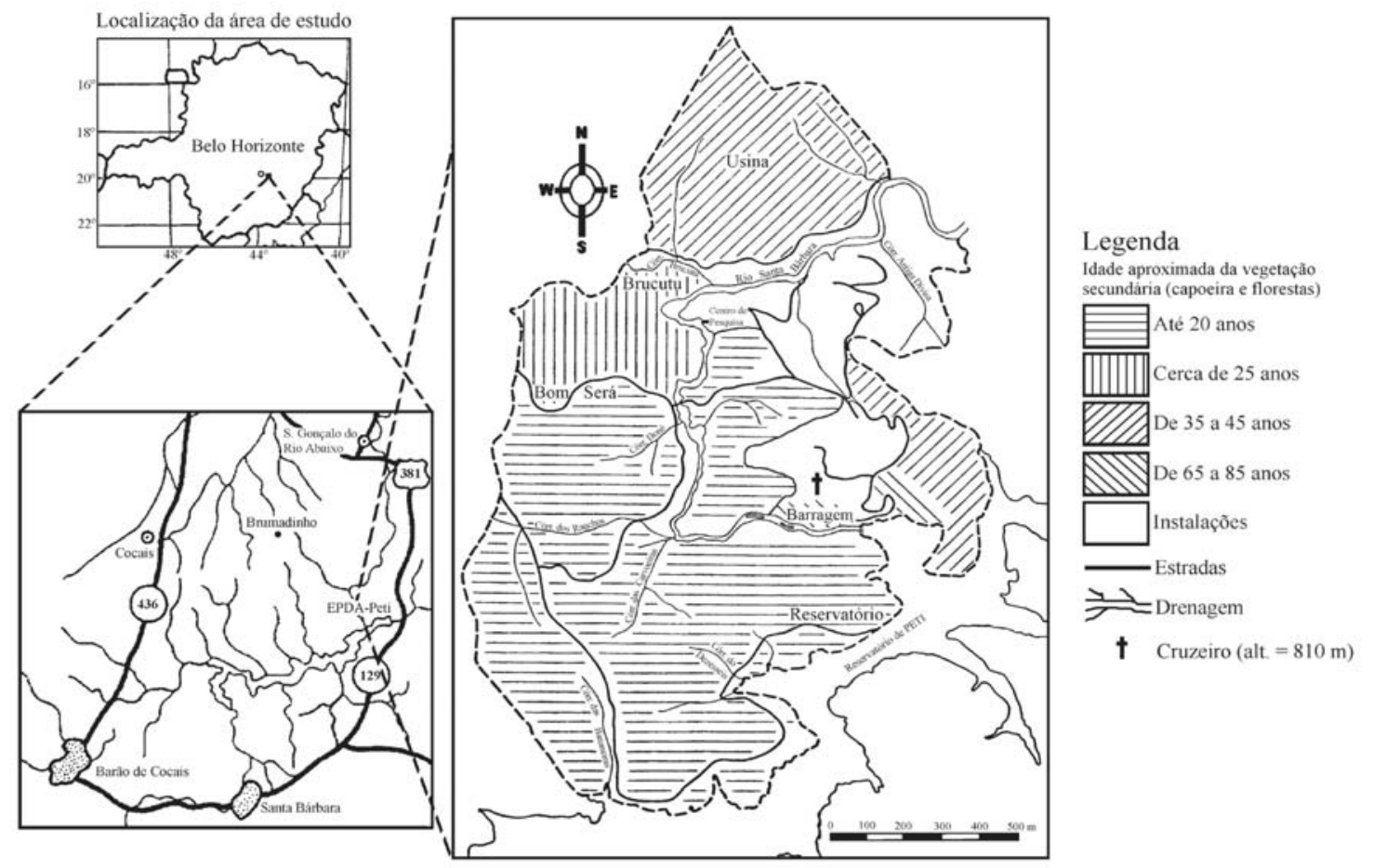

Figura 1 - Localização da Estação de Pesquisa e Desenvolvimento Ambiental de Peti (EPDA-Peti), em Santa Bárbara e São Gonçalo do Rio Abaixo, Minas Gerais, indicando o remanescente florestal (área tracejada) e as áreas de floresta amostradas em diferentes estágios sucessionais. Modificado de Pedralli \& Teixeira (1997).

Figure 1 - Localization of Estação de Pesquisa e Desenvolvimento Ambiental de Peti (EPDA-Peti), Santa Bárbara and São Gonçalo do Rio Abaixo, Minas Gerais, indicating the studied forest fragment (dashed area) and forest areas in different sucessional stages. Modified from Pedralli \& Teixeira (1997).

O solo é classificado como latossolo vermelho amarelo com textura argilosa, afloramentos de rocha e cambissolo e solos litólicos de textura arenosa cascalhenta (CETEC 1989). A vegetação situa-se na transição entre os domínios Tropical Atlântico e dos Cerrados (Rizzini 1979; Veloso 1966; Veloso et al. 1991) e também ocorre sobre afloramento rochoso de gnaisse. Segundo a classificação do IBGE (1993), a vegetação da EPDA-Peti é constituída por floresta estacional semidecidual (floresta tropical subcaducifólia) e pertence ao bioma Mata Atlântica.

Foram realizadas treze campanhas de campo durante os meses de agosto de 2004 a setembro de 2005 para a coleta dos dados de estrutura da vegetação. Para a análise fitossociológica foram escolhidas cinco áreas de floresta em diferentes estágios sucessionais (Fig. 1), sendo realizada a amostragem utilizando-se o método de ponto-quadrante (Cottam \& Curtis 1956; revisão em Martins 1991). Em cada área foram demarcados 48 pontos-quadrantes distando 15 $\mathrm{m}$ entre si e $10 \mathrm{~m}$ da borda das trilhas. Em cada quadrante foi amostrado o indivíduo vivo mais próximo ao ponto, com circunferência do tronco (CAP ou circunferência à altura do peito) à altura de $1,30 \mathrm{~m}$ do solo, igual ou superior a $15 \mathrm{~cm}$. Cada indivíduo recebeu um número de identificação por meio de plaquetas de papelão revestidas de alumínio. Além disso, para cada indivíduo foram registrados a CAP, a altura total, a distância deste até o ponto e a identificação prévia da espécie.

Foram realizadas coletas de material estéril e fértil, quando disponível, de todos os indivíduos amostrados. Aidentificação taxonômica foi feita com base em observações de campo, auxílio de especialistas e comparações com materiais dos herbários BHCB e $\mathrm{HXBH}$. 
Foram feitas também coletas de material fértil para incorporação ao BHCB. A nomenclatura utilizada para as famílias seguiu a classificação utilizada em APG II (2003).

Para a coleta de solo cada área estudada foi dividida em quatro subáreas, sendo realizada uma coleta de solo superficial, de 0 a $20 \mathrm{~cm}$ de profundidade, no centro geométrico de cada subárea. As quatro amostras foram então misturadas e levadas ao laboratório de Química Agrícola do Instituto Mineiro de Agropecuária (IMA), onde foram avaliadas as seguintes características: $\mathrm{pH}$ em água; teores de $\mathrm{Al}, \mathrm{Ca}$, $\mathrm{Mg}, \mathrm{P}$ e K; soma de bases; índice de saturação de bases (V); capacidade de troca de cátions (T); índice de saturação de alumínio (m); matéria orgânica, $\mathrm{C}, \mathrm{N}$ e teores de areia grossa e fina, silte e argila. A comparação das características dos solos foi feita utilizando-se a análise de componentes principais (PCA) após transformação logarítmica das variáveis (Ter Braak 1987); as variáveis expressas em proporção foram transformadas em arco-seno (Zar 1999). As análises foram realizadas utilizando-se o programa PC-ORD for Windows versão 4,14 (McCune \& Mefford 1999).

Os dados fitossociológicos de cada área foram analisados utilizando-se o programa Fitopac 1 (Shepherd 1991). Os parâmetros avaliados foram densidade absoluta e relativa, frequência absoluta e relativa, dominância absoluta e relativa, valor de importância (VI) (Mueller-Dombois \& Ellenberg 1974); índice de diversidade de Shannon (Zar 1999) e equitabilidade correspondente (Pielou 1966). Os resíduos das médias de área basal, diâmetro e altura apresentaram distribuição normal e variâncias homogêneas, sendo comparados entre áreas por análise de variância (ANOVA) seguida de teste de Tukey (Zar 1999), adotando-se nível de significância de 5\%, utilizando-se do programa Statistica 5.0.

Para a análise de similaridade florística entre as áreas foi utilizado o índice de similaridade de Jaccard (Greig-Smith 1983) cuja matriz foi empregada na análise de agrupamento (UPGMA; distância euclidiana). As riquezas de espécies encontradas nas cinco áreas amostradas foram comparadas por meio das curvas médias de acúmulo de espécies (Gotelli \& Colwell 2001), utilizando-se o programa Ecosim - versão 7.0 (Gotelli \& Entsminger 2003) que calculou também os intervalos de confiança (95\%) das médias. As curvas foram construídas com as médias das riquezas obtidas em 1000 re-amostragens de números pré-determinados de indivíduos (10, 20, 30 etc.). As diferenças significativas entre as riquezas estimadas são evidenciadas pela não sobreposição dos intervalos de confiança.

As espécies ameaçadas de extinção foram listadas com base na Lista Oficial das Espécies da Flora Brasileira Ameaçadas de Extinção, do Instituto Brasileiro do Meio Ambiente e dos Recursos Naturais Renováveis - IBAMA (2008).

\section{Resultados e Discussão}

Nos 240 pontos amostrados (área amostral equivalente a 0,42 ha), nas cinco áreas em diferentes estágios sucessionais (Tab. 1; Fig. 1), foram registrados 960 indivíduos pertencentes a 45 famílias, 116 gêneros e 191 espécies (Tab. 2, Apêndice 1 - na vsersão on-line desse artigo).

O número de famílias variou de 21 (Usina) a 29 (Bom Será) (Tab. 2). Considerando-se a reunião das áreas, as famílias com maior número de espécies foram Fabaceae (32 spp.; 16,75\%), Myrtaceae (29 spp.; 15,18\%), Lauraceae (18 spp.; 9,42\%), Melastomataceae (9 spp.; 4,71\%), Euphorbiaceae e Rubiaceae (8 spp. cada; 8,38\%), somando 54,44\% da flora (Tab. 2). Essas mesmas famílias foram as mais ricas em espécies no levantamento florístico realizado na EPDA-Peti por Pedralli \& Teixeira (1997). As áreas amostradas confirmam a representatividade destas famílias nas florestas semidecíduas montanas da região centro-sul de Minas Gerais (Oliveira-Filho et al. 1994a; Carvalho et al. 1995; Botrel et al. 2002; Espírito-Santo et al. 2002; Souza et al. 2003; Sposito \& Stehmann 2006) e em florestas mesófilas semidecíduas de São Paulo (Leitão-Filho 1992).

As áreas Bom Será e Reservatório apresentaram riqueza alta da família Lauraceae 
Tabela 1 - Localização e caracterização das cinco áreas de floresta amostradas na Estação de Pesquisa e Desenvolvimento Ambiental de Peti, Santa Bárbara e São Gonçalo do Rio Abaixo, Minas Gerais.

Table 1 - Localization and characterization of five forest areas in Estação de Pesquisa e Desenvolvimento Ambiental de Peti, Santa Bárbara and São Gonçalo do Rio Abaixo, Minas Gerais.

\begin{tabular}{|c|c|c|c|c|}
\hline Área & Município & $\begin{array}{r}\text { Coordenadas } \\
\text { geográficas }\end{array}$ & $\begin{array}{l}\text { Altitude } \\
\text { (m) }\end{array}$ & Histórico \\
\hline Reservatório & Santa Bárbara & $\begin{array}{l}19^{\circ} 533^{\prime} 45,4^{\prime \prime} \mathrm{S} \\
43^{\circ} 22^{\prime} 06,4^{\prime \prime} \mathrm{W}\end{array}$ & 699 & $\begin{array}{l}\text { Corte raso há } 20 \text { anos*, isolada das demais } \\
\text { áreas pelo reservatório da usina hidrelétrica }\end{array}$ \\
\hline Bom Será & Santa Bárbara & $\begin{array}{l}19^{\circ} 53^{\prime} 16,4^{\prime \prime} \mathrm{S} \\
43^{\circ} 22^{\prime} 28,6^{\prime \prime} \mathrm{W}\end{array}$ & 671 & $\begin{array}{l}\text { Corte raso há } 20-25 \text { anos*, cortada por } \\
\text { estrada de terra e parte inserida na zona } \\
\text { de depleção do rio Santa Bárbara }\end{array}$ \\
\hline Brucutu & Santa Bárbara & $\begin{array}{l}19^{\circ} 52^{\prime} 53,1^{\prime \prime} \mathrm{S} \\
43^{\circ} 22^{\prime} 17,2^{\prime \prime} \mathrm{W}\end{array}$ & 655 & $\begin{array}{l}\text { Corte raso há } 25 \text { anos*, vizinha à mineração } \\
\text { da CVRD e à estrada asfaltada, próxima a } \\
\text { bambuzal e córrego, topografia acentuada }\end{array}$ \\
\hline Usina & Santa Bárbara & $\begin{array}{l}19^{\circ} 52^{\prime} 47,9^{\prime \prime} \mathrm{S} \\
43^{\circ} 22^{\prime} 04,4^{\prime \prime} \mathrm{W}\end{array}$ & 675 & $\begin{array}{l}\text { Corte raso há } 35-45 \text { anos*, próxima de } \\
\text { pasto e estrada asfaltada }\end{array}$ \\
\hline Barragem & $\begin{array}{l}\text { São Gonçalo do } \\
\text { Rio Abaixo }\end{array}$ & $\begin{array}{l}19^{\circ} 53^{\prime} 33,0^{\prime \prime} \mathrm{S} \\
43^{\circ} 22^{\prime} 08,4^{\prime \prime} \mathrm{W}\end{array}$ & 733 & $\begin{array}{l}\text { Corte seletivo há } 65-85^{*} \text { anos, próxima à } \\
\text { barragem da usina hidrelétrica, topografia } \\
\text { acentuada }\end{array}$ \\
\hline
\end{tabular}

* Dados fornecidos, na ocasião, pelo técnico responsável pela Estação de Pesquisa e Desenvolvimento Ambiental de Peti, Santa Bárbara e São Gonçalo do Rio Abaixo, MG. / Informations reported by the responsible technician of the Estação de Pesquisa e Desenvolvimento Ambiental de Peti, Santa Bárbara e São Gonçalo do Rio Abaixo, MG.

(Apêndice 1). Thomaz \& Monteiro (1997) também verificaram alta riqueza dessa família no estado do Espírito Santo e Leitão-Filho (1982) constatou sua presença marcante nos estratos intermediários das comunidades florestais do estado de São Paulo, com alturas de 6-12 m.

Das famílias amostradas, $31,11 \%$ foram representadas por uma única espécie e $22,22 \%$ por duas espécies (Tab. 2). Esses valores podem ser considerados altos quando comparados a alguns trabalhos realizados na Região Sudeste, como Lopes et al. (2002a), Marangon et al. (2003) e Ivanauskas et al. (1999), onde os mesmos variaram de $9,64 \%$ a $21,64 \%$ de famílias com uma espécie e de $5,58 \%$ a $10,31 \%$ com duas espécies,

A Figura 2 ilustra os valores de importância (VI) para famílias encontradas. Fabaceae, Euphorbiaceae, Myrtaceae, Anacardiaceae e Sapindaceae somaram $67,09 \%$ do VI na Estação como um todo. Fabaceae e Myrtaceae estão entre as famílias mais representativas na maioria dos levantamentos florísticos realizados em florestas semidecíduas dos estados de São Paulo e Minas Gerais (Pagano \& Leitão Filho 1987; Meira-
Neto \& Martins 2000; Meyer et al. 2004). Observa-se que Fabaceae foi a família com maior VI em quatro áreas (Reservatório, Bom Será, Brucutu e Usina) e na EPDA-Peti como um todo. Além de se apresentar como a família mais rica (Apêndice 1), os indivíduos contribuíram para o incremento dos valores de densidade relativa, dominância relativa e frequência relativa, que foram os mais elevados quando comparados às demais famílias. Fabaceae apresenta-se bem distribuída na região tropical, colonizando especialmente solos pobres em sucessão secundária, fato provavelmente influenciado pela presença em suas raízes de bactérias capazes de fixar nitrogênio atmosférico (Salisbury \& Ross 1992).

A área Barragem, de estágio sucessional mais avançado, apresentou Euphorbiaceae como família mais importante, especialmente devido aos valores elevados de densidade relativa e frequência relativa de Aparisthmium cordatum, espécie classificada como secundária inicial (Lopes et al. 2002a), Mabea fistulifera, espécie característica dos estádios iniciais de sucessão primária (Lopes et al. 2002a; Paula et al. 2004) 
Tabela 2 - Características fitossociológicas do componente arbóreo de cinco áreas de floresta amostradas na Estação de Pesquisa e Desenvolvimento Ambiental de Peti, Santa Bárbara e São Gonçalo do Rio Abaixo, MG. Letras diferentes indicam diferença significativa pelo teste de Tukey $(5 \%) . H^{\prime}=$ Índice de diversidade de Shannon (nats/indivíduo), logaritmo na base $e . \mathrm{RES}=$ Reservatório; BOMS = Bom Será; BRU = Brucutu; USI = Usina; BAR = Barragem.

Table 2 - Phytossociological characteristics of arboreal component of five forest areas in Estação de Pesquisa e Desenvolvimento Ambiental de Peti, Santa Bárbara and São Gonçalo do Rio Abaixo, MG. Different letters indicate significant difference for Tukey test (5\%). H' = Diversity Index of Shannon (nats/indivvdual), logarithm with base $e$. RES = Reservatório; BOMS = Bom Será; BRU = Brucutu; USI = Usina; BAR = Barragem.

\begin{tabular}{|c|c|c|c|c|c|c|}
\hline & RES & BOMS & BRU & USI & BAR & TOTAL \\
\hline Número de famílias & 28 & 29 & 24 & 21 & 28 & 45 \\
\hline Número de gêneros & 55 & 59 & 47 & 51 & 64 & 116 \\
\hline Número de espécies & 76 & 68 & 64 & 64 & 80 & 191 \\
\hline \multicolumn{7}{|l|}{$\begin{array}{l}\text { Famílias com maior } \\
\text { número de espécies }(\%)\end{array}$} \\
\hline Euphorbiaceae & 5,3 & 5,9 & 4,7 & 7,7 & 8,5 & 4,2 \\
\hline Fabaceae & 28,0 & 18,8 & 20,6 & 32,3 & 13,4 & 16,8 \\
\hline Lauraceae & 10,7 & 13,0 & 7,8 & 0,0 & 8,5 & 9,4 \\
\hline Melastomataceae & 2,6 & 1,5 & 1,6 & 6,2 & 5,0 & 4,7 \\
\hline Myrtaceae & 5,3 & 11,6 & 23,8 & 15,4 & 17,1 & 15,2 \\
\hline Rubiaceae & 0,0 & 2,9 & 3,1 & 0,0 & 5,0 & 4,2 \\
\hline $\begin{array}{l}\text { Famílias representadas } \\
\text { por } 1 \text { espécie }(\%)\end{array}$ & 46,4 & 62,0 & 62,5 & 47,6 & 42,8 & 31,1 \\
\hline $\begin{array}{l}\text { Famílias representadas } \\
\text { por } 2 \text { espécies }(\%)\end{array}$ & 28,6 & 17,2 & 12,5 & 28,6 & 25,0 & 22,2 \\
\hline $\begin{array}{l}\text { Espécies ocorrentes } \\
\text { somente nesta área (\%) }\end{array}$ & 11,6 & 7,9 & 7,4 & 10,0 & 16,9 & - \\
\hline \multicolumn{7}{|l|}{ \% Classes de diâmetro $(\mathrm{cm})$} \\
\hline $5,0-10$ & 53,6 & 66,1 & 55,2 & 74,5 & 47,4 & - \\
\hline $10,1-20$ & 35,9 & 31,8 & 39,6 & 22,4 & 41,7 & - \\
\hline $20,1-30$ & 8,3 & 1 & 3,6 & 2,6 & 8,3 & - \\
\hline $30,1-40$ & 1 & 0,5 & 1,6 & 0 & 2,1 & - \\
\hline $40,1-50$ & 0 & 0,5 & 0 & 0,5 & 0 & - \\
\hline $50,1-60$ & 1 & 0 & 0 & 0 & 0 & - \\
\hline $60,1-70$ & 0 & 0 & 0 & 0 & 0,5 & - \\
\hline \multicolumn{7}{|l|}{$\%$ Classes de altura (m) } \\
\hline $2,1-5$ & 4,7 & 5,2 & 4,2 & 17,7 & 10,4 & - \\
\hline $5,1-10$ & 65,6 & 75,5 & 65,6 & 71,9 & 55,7 & - \\
\hline $10,1-15$ & 29,7 & 19,3 & 29,7 & 9,9 & 29,7 & - \\
\hline $15,1-20$ & 0 & 0 & 0,5 & 0,5 & 3,6 & - \\
\hline 20,1 a 23 & 0 & 0 & 0 & 0 & 0,5 & - \\
\hline Diâmetro médio (cm) & $11,4 \pm 7,1^{\mathrm{c}}$ & $9,6 \pm 5,0^{\mathrm{ab}}$ & $10,9 \pm 5,6^{\mathrm{bc}}$ & $8,9 \pm 5,1^{\mathrm{a}}$ & $12,1 \pm 7,1^{\mathrm{c}}$ & $10,6 \pm 6,2$ \\
\hline Diâmetro máximo (cm) & 51 & 40,3 & 33,3 & 47,8 & 61,8 & 61,8 \\
\hline Altura média (m) & $8,6 \pm 2,1^{\mathrm{cd}}$ & $8,2 \pm 2,2^{\mathrm{bc}}$ & $9,1 \pm 2,4^{\mathrm{d}}$ & $7,1 \pm 2,1^{\mathrm{a}}$ & $9,2 \pm 3,4^{\mathrm{d}}$ & $8,4 \pm 2,6$ \\
\hline Altura máxima (m) & 14 & 14 & 15,5 & 16 & 23 & 23 \\
\hline Densidade relativa (ind.ha ${ }^{-1}$ ) & 1888 & 2924 & 2471 & 2381 & 1891 & - \\
\hline Área basal $\left(\mathrm{m}^{2} \cdot \mathrm{ha}^{-1}\right)$ & $26,69^{\mathrm{bc}}$ & $27,09^{\mathrm{ab}}$ & $29,16^{\mathrm{abc}}$ & $19,44^{\mathrm{a}}$ & $29,33^{\mathrm{c}}$ & - \\
\hline H' espécies & 3,877 & 3,882 & 3,59 & 3,761 & 3,89 & 4,508 \\
\hline H’ famílias & 2,535 & 2,623 & 2,245 & 2,276 & 2,653 & 2,686 \\
\hline J espécies (equitabilidade) & 0,898 & 0,917 & 0,866 & 0,901 & 0,883 & 0,856 \\
\hline
\end{tabular}



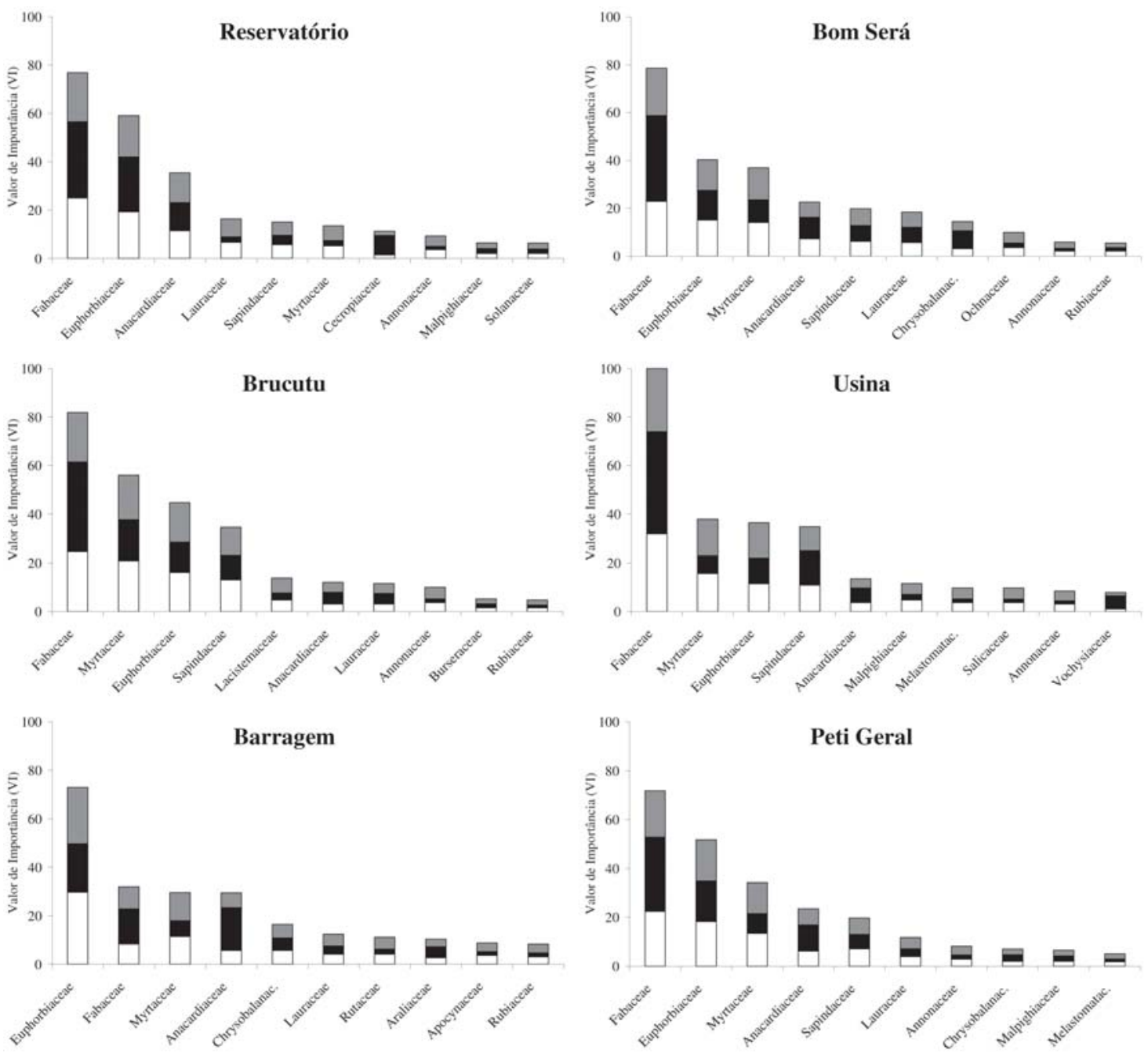

Figura 2 - Densidade relativa $\square$, dominância relativa e frequência relativa das famílias de maior Valor de importância (VI), nas cinco áreas de floresta (Reservatório, Bom Será, Brucutu, Usina e Barragem) e em todas as áreas (Peti Geral) amostradas na Estação de Pesquisa e Desenvolvimento Ambiental de Peti, Santa Bárbara e São Gonçalo do Rio Abaixo, Minas Gerais.

Figure 2 - Relative density $\square$, relative dominance $\square$ and relative frequency $\square$ of families with major importance value (VI) in five forest areas (Reservatório, Bom Será, Brucutu, Usina e Barragem) and in all areas simultaneously (Peti Geral) in Estação de Pesquisa e Desenvolvimento Ambiental de Peti, Santa Bárbara and São Gonçalo do Rio Abaixo, Minas Gerais.

e Pogonophora schomburgkiana, espécie considerada secundária tardia. Uma possível explicação para tal diferenciação florística encontrada na área Barragem, além do estágio sucessional, é a presença de maior umidade devido à proximidade desta área ao vertedouro da usina hidrelétrica. A presença de espécies de sucessão inicial com alto VI indica que a área, apesar do tempo de recuperação, ainda apresenta distúrbios que afetam sua reestruturação natural como, por exemplo, a manutenção de várias trilhas de cerca de $2 \mathrm{~m}$ de largura, que concentram grande quantidade de bambus (Merostachys cf. kunthii) em suas bordas.

O número de gêneros variou de 47 (Brucutu) a 64 (Barragem) (Tab. 2). Considerando-se as cinco áreas, os gêneros com o maior número de espécies foram Ocotea (10), Eugenia e Miconia (7 cada), Machaerium (6) e Myrcia (5) (Apêndice 1), contribuindo com 18,3\% das espécies. Esses mesmos gêneros apresentaram o maior número de espécies para a flora 
arbórea de 36 áreas de floresta atlântica da região sudeste (Oliveira-Filho \& Fontes 2000).

O número de espécies variou de 64 (Brucutu) a 80 (Barragem) (Tab. 2). Astronium fraxinifolium, Tapirira obtusa, Mabea fistulifera, Pogonophora schomburgkiana, Apuleia leiocarpa, Cassia ferruginea, Dalbergia nigra, Machaerium brasiliense, Platypodium elegans e Byrsonima sericea foram amostradas em todas as áreas e representaram 5,2\% das 191 espécies encontradas (Apêndice 1). As maiores populações, considerando-se todas as áreas, pertenceram a Pogonophora schomburgkiana (50 indivíduos), Cupania ludowigii (44), que ocorre na Mata Atlântica da Bahia, Espírito Santo, Minas Gerais e Rio de Janeiro (Somner \& Ferrucci 2004), Astronium fraxinifolium (34) e Mabea fistulifera (34) (Apêndice 1). Astronium fraxinifolium, Mabea fistulifera e Platypodium elegans são consideradas generalistas da Mata Atlântica na Região Sudeste (Oliveira-Filho \& Fontes 2000).

Das 191 espécies amostradas, 102 (53,4\%) ocorreram apenas em uma área, 45 (23,6\%) em duas áreas e 32 (16,7\%) ocorreram em três ou quatro áreas. Esses dados indicam heterogeneidade florística entre as áreas. Entre as dez espécies de maior VI, considerando-se todas as áreas, não há nenhuma comum às cinco áreas (Fig. 3). Mabea fistulifera e Apuleia leiocarpa foram espécies de destaque em VI em quatro áreas; Mabea fistulifera só não foi destaque em VI na área Bom Será e Apuleia leiocarpa só não foi destaque em VI na área Barragem. Dalbergia nigra e Platypodium elegans foram, respectivamente, espécies de destaque em VI somente em Brucutu e em Usina.

Em todas as áreas, a maior proporção de indivíduos encontra-se na classe de 5,0 a $10,0 \mathrm{~cm}$ de diâmetro e 5,1 a 10,0 m de altura (Tab. 2). A Barragem apresentou, em relação às demais áreas, uma proporção maior de indivíduos na classe de altura de 15,1 a 20,0 m. A primeira classe apresentou-se com frequência menor do que a classe seguinte; esse comportamento foi observado por outros autores (Martins 1991; Lopes et al. 2002a) e pode ser devido ao critério de inclusão, que excluiu os indivíduos que ainda não tinham atingido CAP de $15 \mathrm{~cm}$, mas que já tinham altura equivalente à primeira classe. Tais distribuições com formato de "J" invertido também podem ser atribuídas ao processo natural de regeneração, com constante recrutamento e mortalidade de indivíduos (Harper 1977; Scolforo et al. 1998).

Foram encontrados indivíduos emergentes de Tapirira obtusa, Guatteria odontopetala, Copaifera langsdorffii, Sclerolobium rugosum e Cassia ferruginea na área Barragem, Plathymenia foliolosa na área Brucutu, Apuleia leiocarpa nas áreas Barragem e Usina, Croton urucurana na área Usina, com média de $15 \mathrm{~m}$ de altura (Apêndice 1). Indivíduos emergentes são característicos de florestas clímax ou em estágio tardio da sucessão nas regiões tropicais (Richards 1975).

A pequena quantidade de árvores de grande porte, os baixos valores de área basal por hectare e a alta densidade de árvores (Tab. 2) decorrem de corte aplicado no passado para abastecer especialmente a indústria do carvão (exceto na área Barragem, que sofreu corte seletivo devido à declividade acentuada do terreno). Apesar da área Barragem ter sofrido corte há mais tempo em relação às demais áreas, a altura, o diâmetro e a área basal das árvores de Reservatório e Brucutu não apresentaram diferenças significativas em suas estruturas comparadas à área Barragem, somente as áreas Bom Será e Usina apresentaram tais diferenças (Tab. 2). Segundo Whitmore (1990) a intensidade da perturbação sofrida por uma floresta tropical interfere na sua velocidade de regeneração. Tabarelli \& Mantovani (1999) observaram que uma floresta paulista montana, após corte e queima, restaura em ordem decrescente de velocidade a riqueza e diversidade de espécies e por último os atributos da estrutura física, exceto densidade de indivíduos. O presente trabalho não evidencia um padrão claro de aumento de riqueza e diversidade de espécies e estrutura dos indivíduos amostrados em função do aumento do tempo de sucessão, e sim aponta para um conjunto complexo de processos envolvidos na regeneração florestal. 

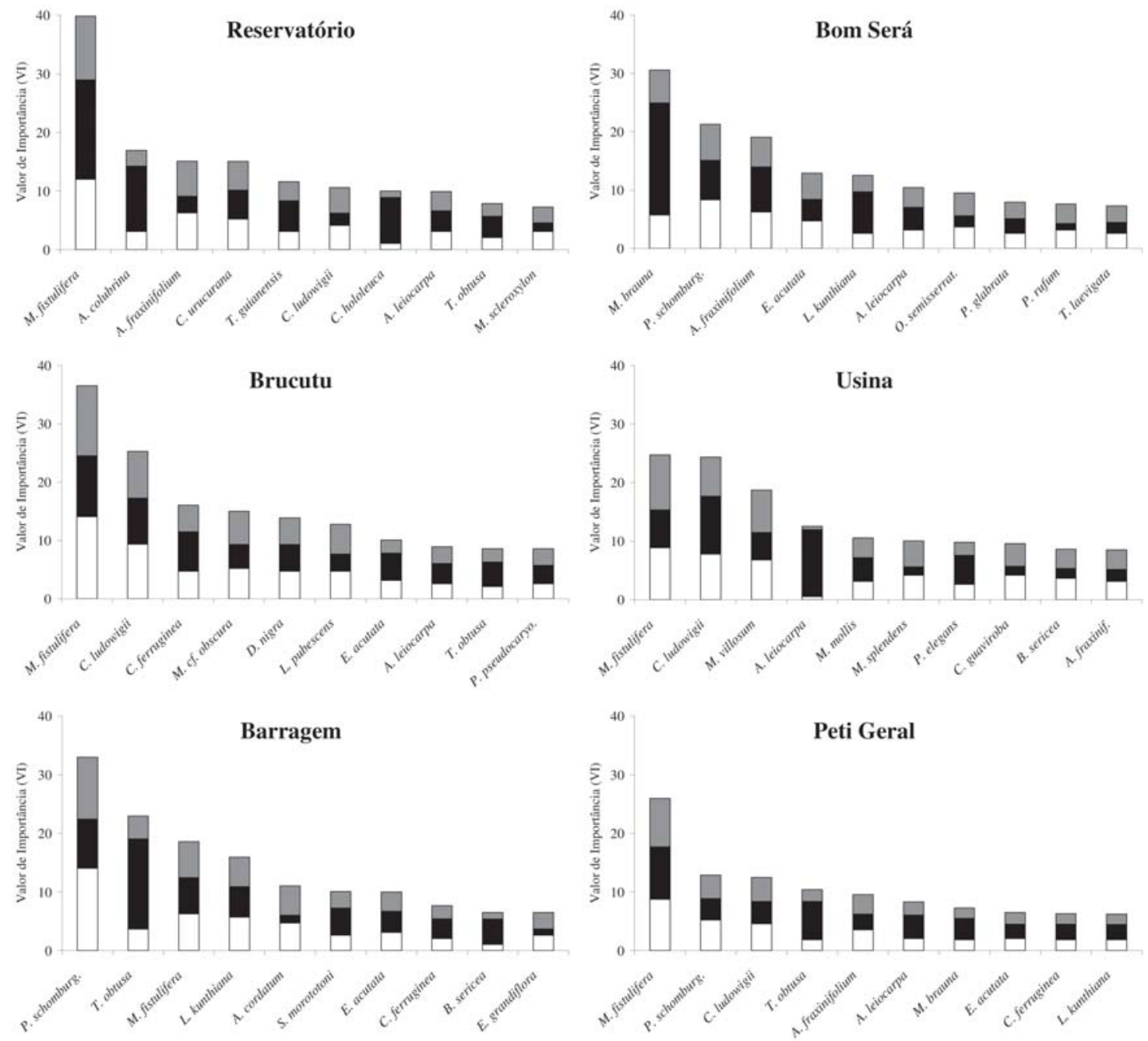

Figura 3 - Densidade relativa $\square$, dominância relativa $\square$ e frequência relativa $\square$ das espécies de maior valor de importância (VI), nas cinco áreas de floresta (Reservatório, Bom Será, Brucutu, Usina e Barragem) e em todas as áreas (Peti Geral) amostradas na Estação de Pesquisa e Desenvolvimento Ambiental de Peti, Santa Bárbara e São Gonçalo do Rio Abaixo, Minas Gerais.

Figure 3 - Relative density $\square$, relative dominance $\square$ and relative frequency $\square$ of species with major importance value (VI) in five forest areas (Reservatório, Bom Será, Brucutu, Usina e Barragem) and in all areas simultaneously (Peti Geral) in Estação de Pesquisa e Desenvolvimento Ambiental de Peti, Santa Bárbara and São Gonçalo do Rio Abaixo, Minas Gerais.

Outras características, entretanto, permitemnos diagnosticar essa diferença de idade entre as áreas, como a serrapilheira, que se apresenta mais desenvolvida na área Barragem, e a luminosidade, visivelmente mais intensa nas demais áreas, propiciando colonização por capim-navalha (Scleria pterota e Rhynchospora exaltata Cyperaceae). Entretanto, na área Usina, mais antiga que Bom Será, Reservatório e Brucutu, também pode ser observada maior quantidade dessas espécies, particularmente numa vertente mais seca que está sujeita a maior incidência de radiação solar no período mais quente do dia. Também nessa área, o índice de saturação de alumínio foi maior do que nas demais (Tab. 4), fator que provavelmente contribuiu para a colonização por Cyperaceae (Silva 1996).

Ocorte raso ou seletivo parece ter favorecido as espécies que rebrotam, uma vez que muitos indivíduos com poucas ou múltiplas rebrotas foram observados nas áreas amostradas. Esse mecanismo de regeneração é importante para 
muitas espécies manterem sua população na floresta. De acordo com Hartshorn (1989), as rebrotas aparecem com mais frequiência em locais cortados do que em clareiras naturais. Uhl et al. (1988) observaram que plântulas originárias de propágulos dispersados ou do banco de sementes tinham menor chance de ocuparem as clareiras do que os indivíduos jovens ou adultos que sobreviveram ao distúrbio, isto é, que haviam rebrotado.

Os índices de diversidade de Shannon são apresentados na Tabela 2. Considerando-se todas as áreas amostradas, este índice foi de 4,508 nats/indivíduo. Este valor foi maior do que o que tem sido geralmente observado em outras matas semidecíduas e no estado de Minas Gerais (Lopes et al. 2002b). Os resultados estão de acordo com Oliveira-Filho (1989), que observou que este índice aumenta devido às diferenças florísticas encontradas entre os setores amostrais da floresta, que individualmente apresentam índices mais baixos. No caso das florestas amostradas, acredita-se que esse valor elevado do índice esteja associado especialmente ao fato da EPDA-Peti apresentar-se como um mosaico sucessional decorrente da ação humana (corte raso da vegetação, com abertura de clareiras).

Os valores de equitabilidade (J') para as espécies variaram de 0,866 (Brucutu) a 0,917
(Bom Será) (Tab. 2), mostrando não haver forte dominância na abundância de determinadas espécies.

Os valores de riqueza observada e estimada, com os respectivos intervalos de confiança (95\%), foram listados para uma amostra de 192 indivíduos (Tab. 3). A área Barragem, que sofreu corte seletivo, apresentou riqueza de espécies significativamente maior do que as demais áreas e Brucutu e Usina destacaramse com riqueza estimada de espécies menor que a das outras áreas, as quais apresentaram riquezas estimadas intermediárias. Segundo Richards (1975), áreas que sofreram corte seletivo apresentam uma rica comunidade constituída de espécies de floresta primária e secundária, de estrutura bastante irregular, visto que as últimas ocupam as clareiras formadas pela retirada dos indivíduos da comunidade.

$\mathrm{O}$ índice de similaridade de Jaccard indicou dissimilaridade entre as áreas, apesar de terem sido formados dois grupos florísticos: as maiores similaridades ocorreram, de um lado, entre as áreas Bom Será, Usina e Reservatório e, de outro lado, entre as áreas Brucutu e Barragem (Fig. 4). Apesar da área Barragem e Brucutu possuírem histórico de ocupação diferente (corte seletivo e corte raso, respectivamente), essas áreas apresentaram maior similaridade. Essas são as áreas de

Tabela 3 - Riqueza observada e estimada de espécies arbóreas e respectivos intervalos de confiança (95\%), se 192 indivíduos fossem amostrados, em cinco áreas de floresta amostradas na Estação de Pesquisa e Desenvolvimento Ambiental de Peti, Santa Bárbara e São Gonçalo do Rio Abaixo, Minas Gerais. $\mathrm{N}=$ Número de árvores. Letras diferentes indicam diferenças significativas ( $\mathrm{p}<$ 0,05). RES = Reservatório; BOMS = Bom Será; BRU = Brucutu; USI = Usina; BAR = Barragem.

Table 3 - Observed and estimated richness of arboreal species and respectives confidence intervals (95\%), if 192 individuals were surveyed, in five forest areas in Estação de Pesquisa e Desenvolvimento Ambiental de Peti, Santa Bárbara and São Gonçalo do Rio Abaixo, Minas Gerais. N = number of trees. Different letters indicate significant differences $(\mathrm{p}<0,05)$. RES = Reservatório; BOMS = Bom Será; BRU = Brucutu; USI = Usina; BAR = Barragem.

\begin{tabular}{lcccc}
\hline ÁREA & N & Riqueza observada & Riqueza estimada & Intervalo de Confiança (95\%) \\
\hline RES & 192 & 75 & $74,6 \mathrm{c}$ & $73-75$ \\
BOMS & 192 & 69 & $68,7 \mathrm{~b}$ & $68-69$ \\
BRU & 192 & 64 & $63,7 \mathrm{a}$ & $62-64$ \\
USI & 192 & 65 & $63,7 \mathrm{a}$ & $63-64$ \\
BAR & 192 & 80 & $79,5 \mathrm{~d}$ & $74-80$ \\
\hline
\end{tabular}


Tabela 4 - Características do solo das cinco áreas de floresta amostradas na Estação de Pesquisa e Desenvolvimento Ambiental de Peti, Santa Bárbara e São Gonçalo do Rio Abaixo, Minas Gerais. RES = Reservatório; BOMS = Bom Será; BRU = Brucutu; USI = Usina; BAR = Barragem.

Table 4 - Soil properties of five forest areas in Estação de Pesquisa e Desenvolvimento Ambiental de Peti, Santa Bárbara and São Gonçalo do Rio Abaixo, Minas Gerais. RES = Reservatório; BOMS = Bom Será; BRU = Brucutu; USI = Usina; $\mathrm{BAR}=$ Barragem.

\begin{tabular}{|c|c|c|c|c|c|}
\hline Componentes e Características do solo & RES & BOMS & BRU & USI & BAR \\
\hline pH em água & 4,40 & 4,60 & 4,60 & 4,55 & 4,40 \\
\hline $\mathrm{H}+\mathrm{Al}$ & 7,87 & 7,70 & 9,61 & 16,42 & 7,04 \\
\hline $\mathrm{Al}^{+++}\left(\mathrm{cmolc}^{\mathrm{d}} \mathrm{dm}^{3}\right)$ & 1,50 & 2,12 & 2,49 & 3,47 & 1,68 \\
\hline $\mathrm{Ca}^{++}\left(\mathrm{cmolc} . \mathrm{dm}^{3}\right)$ & 0,15 & 0,20 & 0,08 & 0,13 & 0,12 \\
\hline $\mathrm{Mg}^{++}\left(\mathrm{cmolc} . \mathrm{dm}^{3}\right)$ & 0,09 & 0,09 & 0,07 & 0,11 & 0,08 \\
\hline $\mathrm{K}\left(\mathrm{mg} \cdot \mathrm{dm}^{3}\right)$ & 33,00 & 56,00 & 26,00 & 38,50 & 33,00 \\
\hline Soma de Bases (cmolc.dm³) & 0,32 & 0,44 & 0,21 & 0,35 & 0,29 \\
\hline $\mathrm{T}$ - Capacidade de troca de cátions $\left(\mathrm{cmolc} \cdot \mathrm{dm}^{3}\right.$ ) & 8,20 & 8,13 & 9,82 & 16,77 & 7,33 \\
\hline $\mathrm{t}$-Capacidade efetiva de troca de cátions $\left(\mathrm{cmolc} \cdot \mathrm{dm}^{3}\right)$ & 1,82 & 2,56 & 2,70 & 3,81 & 1,97 \\
\hline m - Índice de saturação de alumínio (\%) & 82,20 & 83,00 & 92,30 & 90,87 & 85,26 \\
\hline V - Índice de saturação de bases (\%) & 3,95 & 5,35 & 2,11 & 2,05 & 3,97 \\
\hline Matéria orgânica (dag. $\left.\mathrm{kg}^{-1}\right)$ & 3,47 & 3,34 & 4,28 & 5,63 & 2,60 \\
\hline $\mathrm{C}\left(\right.$ dag.kg $\left.\mathrm{kg}^{-1}\right)$ & 2,01 & 1,94 & 2,48 & 3,27 & 1,51 \\
\hline $\mathrm{N}\left(\right.$ dag. $\left.\mathrm{kg}^{-1}\right)$ & 0,17 & 0,17 & 0,21 & 0,25 & 0,13 \\
\hline Areia grossa $(\%)$ & 39,90 & 41,30 & 10,00 & 11,10 & 40,10 \\
\hline Areia fina $(\%)$ & 27,60 & 28,70 & 45,20 & 34,30 & 25,00 \\
\hline Silte $(\%)$ & 8,88 & 10,24 & 18,16 & 16,60 & 12,34 \\
\hline Argila (\%) & 23,62 & 19,76 & 26,64 & 38,00 & 22,56 \\
\hline
\end{tabular}

relevo mais acidentado e de maior proximidade aos cursos d'água. Variáveis como topografia (Cardoso \& Schiavini 2002; Oliveira-Filho et al. 1994b; Botrel et al. 2002) e constituição e regime de água dos solos (Oliveira-Filho et al. 1994b; Botrel et al. 2002; Souza et al. 2003; Espírito-Santo et al. 2002, Rocha et al. 2005) são determinantes na distribuição de espécies arbóreas em fragmentos de florestas semidecíduas e montanas em geral. Diferenças encontradas na composição florística do estrato arbóreo são características marcantes das florestas tropicais (Giraldo-Cañas 2000; Oliveira Filho \& Fontes 2000). Sposito \& Stehmann (2006) também encontraram alta heterogeneidade florística entre oito fragmentos de floresta na região metropolitana de Belo Horizonte, com distâncias entre as áreas até $60 \mathrm{~km}$.

Os níveis de alumínio encontrados nos solos das áreas amostradas são altos quando comparados a outras áreas de florestas estacionais semideciduais (Sposito \& Stehmann 2006) (Tab. 4). No entanto, a maioria dos estudos florísticos não inclui tabelas de análise de solo em seus trabalhos, impossibilitando uma comparação mais ampla. No Brasil, elevados teores de alumínio são característicos de solos do Cerrado, mas o caráter álico já foi também descrito em florestas tropicais (Silva \& LeitãoFilho 1982; Rodrigues 1989).

As amostras apresentaram baixa saturação por bases (V inferior a 50\%) (EMBRAPA 1999), portanto, baixa concentração de cátions básicos trocáveis (Tab. 4). As capacidades de troca de cátions correspondentes à fração argila (T) encontradas para as diferentes áreas também foram baixas, já que os valores foram inferiores a $27 \mathrm{cmol} / \mathrm{kg}$ (EMBRAPA 1999). Certamente, o empobrecimento do solo foi ocasionado pela ação da água sobre o mesmo, gerando lixiviação 


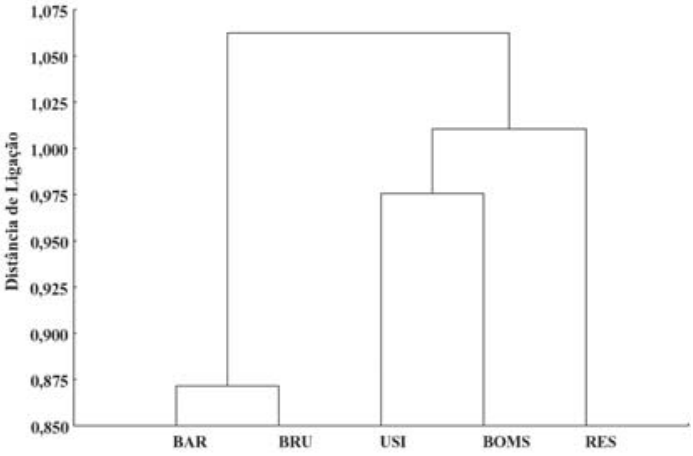

Figura 4 - Dendrograma de similaridade florística a partir do Índice de Jaccard (UPGMA; distância euclidiana) das cinco áreas de floresta amostradas na Estação de Pesquisa e Desenvolvimento Ambiental de Peti, Santa Bárbara e São Gonçalo do Rio Abaixo, Minas Gerais. BAR = Barragem; BRU = Brucutu; USI = Usina $;$ BOMS = Bom Será; RES = Reservatório.

Figure 4 - Floristic similarity dendrogram with Jaccard index (UPGMA; euclidian distance) of five forest areas in Estação de Pesquisa e Desenvolvimento Ambiental de Peti, Santa Bárbara and São Gonçalo do Rio Abaixo, Minas Gerais. $\mathrm{BAR}=$ Barragem; $\mathrm{BRU}=$ Brucutu; USI = Usina; $\mathrm{BOMS}=$ Bom Será; RES = Reservatório.

dos nutrientes, já que essas áreas sofreram corte raso ou seletivo. Entretanto, o solo é capaz de sustentar a mata por apresentar grande quantidade de matéria orgânica superficial (EMBRAPA 1999) (Tab. 4), permitindo, dessa forma, a ciclagem rápida de nutrientes.

Segundo Buckman \& Brady (1968) os solos moderadamente ácidos parecem ser bastante satisfatórios para o desenvolvimento da vegetação em geral. Os ácidos são formados a partir da decomposição da matéria orgânica; já os fenômenos de intemperismo liberam as bases permutáveis que ficam, então, disponíveis para adsorção. A acidez do solo é comum em todas as regiões em que a quantidade de chuvas é suficientemente elevada para lixiviar grande quantidade de bases permutáveis das camadas superficiais de solos. No caso das áreas amostradas, o escoamento da água da chuva após a retirada da vegetação para produção de carvão provavelmente permitiu a lixiviação de nutrientes e consequente elevação da acidez do solo (Tab. 4). Um solo ácido, por sua vez, apresentará teores reduzidos de cálcio e magnésio permutáveis e elevada solubilidade de alumínio (Buckman \& Brady 1968), como é o caso das áreas estudadas.

Em geral, os solos de textura média (hipoteticamente: $35 \%$ de argila, $40 \%$ de areia e $25 \%$ de silte) são os de maior eficiência produtiva, pois mantém maior disponibilidade de água para as plantas, propiciam o desenvolvimento do sistema radicular em profundidade e drenam facilmente qualquer excesso d'água (Silva 1996). Os resultados encontrados para a granulometria das partículas (areia grossa, areia fina, silte e argila) (Tab. 4) caracterizam os solos das áreas Bom Será, Reservatório e Barragem como arenosos (EMBRAPA 1999).

$\mathrm{Na}$ análise de componentes principais (PCA) realizada com a matriz de correlação dos dados de solo (Fig. 5), em que cada componente contribui igualmente para a solução da análise, os autovalores obtidos foram bastante baixos, indicando que a contribuição dos componentes para a variância total dos dados foi muito pequena. As únicas variáveis que apresentaram autovalores dos três primeiros eixos da PCA acima de 0,4 foram areia grossa, potássio e soma de bases, sendo as duas últimas fortemente correlacionadas. Portanto, não foram selecionadas variáveis para a realização da análise de correspondência canônica, ou CCA (Ter Braak 1987). Apesar dos baixos autovalores, o primeiro eixo apresentou variância de 75,3\% e o segundo, 18,3\%. Na PCA realizada com os dados de abundância das espécies, os autovalores obtidos também se apresentaram muito baixos. No entanto, a variância obtida para o primeiro eixo foi de $41,6 \%$, para o segundo eixo, de $28,5 \%$ e para o terceiro eixo, $19,4 \%$. Provavelmente o solo não correspondeu ao fator determinante das diferenças florísticas e estruturais encontradas entre as áreas.

Foram encontradas nas áreas amostradas três espécies arbóreas ameaçadas de extinção: Ocotea odorifera (Vell.) Rohwer, Dalbergia nigra Allem. ex Benth. e Melanoxylon brauna Schott., sendo identificados muitos indivíduos jovens das duas últimas espécies citadas (IBAMA, Instrução Normativa ${ }^{\circ} 06$, de 23/09/2008).

A importância da EPDA-Peti como Unidade de Conservação é ressaltada ao se verificar que áreas bastante próximas possuem 

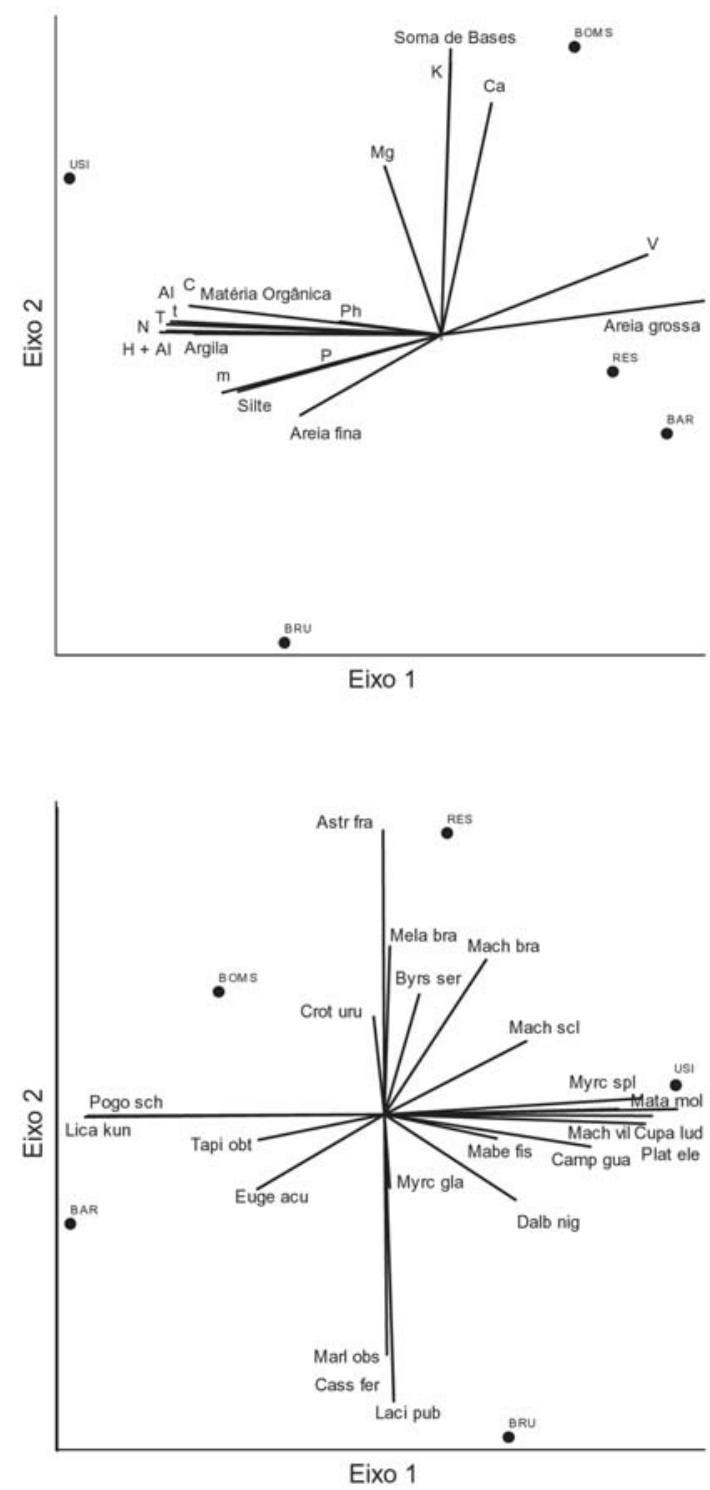

Figura 5 - Análises de componentes principais (PCAs) das características do solo (legendas na tabela 4) e da abundância de espécies arbóreas para cinco áreas de floresta amostradas na Estação de Pesquisa e Desenvolvimento Ambiental de Peti, Santa Bárbara e São Gonçalo do Rio Abaixo, Minas Gerais. RES = Reservatório; BOMS = Bom Será; BRU = Brucutu; $\mathrm{USI}=\mathrm{Usina} ; \mathrm{BAR}=$ Barragem .

Figure 5 - Principal components analysis of soil properties (legends on Table 4) and of arboreal species abundance for five forest areas of Estação de Pesquisa e Desenvolvimento Ambiental de Peti, Santa Bárbara and São Gonçalo do Rio Abaixo, Minas Gerais. RES = Reservatório; BOMS = Bom Será; BRU $=$ Brucutu; USI $=$ Usina; BAR $=$ Barragem . muitas espécies diferentes. Nesse sentido, a reserva funciona como uma rica fonte de diásporos para áreas adjacentes que venham a entrar em sucessão vegetal, já que possui alta diversidade vegetal em meio a uma região com histórico de intensa degradação ambiental.

\section{Agradecimentos}

Ao Programa de Estudos Ecológicos de Longa Duração - PELD/CNPq o financiamento dos trabalhos de campo, à Fundação de Amparo à Pesquisa de Minas Gerais - FAPEMIG a concessão de bolsa de estudos à primeira autora, aos especialistas que auxiliaram na identificação das plantas férteis, Renato Goldenberg (UFPR, Melastomataceae), Alexandre Quinet (JBRJ, Lauraceae), Marcos Sobral (UFMG, Myrtaceae), Aristônio Teles (UFMG, Asteraceae); Alexandre Salino (UFMG), Júlio Lombardi (UFMG), Ary Oliveira-Filho (UFLA) e Rubens Mota o auxílio na identificação do material vegetativo. Marcel França (UFMG) e Claúdia Sampaio, pela contribuição na análise de solos e à Cinthia Tamara, o auxílio nas análises estatísticas. Ao professor Alexandre Silva (in memoriam) e Leonardo Lopes a leitura crítica do manuscrito. Ao colega Leotacílio e demais funcionários da EPDA-Peti.

\section{REFERÊNCIAS BIBLIOGRÁFICAS}

ANA. 2008. Agência Nacional de Águas. Dados pluviométricos disponíveis em http:/ /200.140.135.132/PortalSuporte/ frmVisulizaEstacao.html?kml=http:// 200.140.135.132/PortalSuporte/temp/ A1214289530.kml. Acessado em 06 de agosto de 2008.

Antunes, F.Z. 1986. Caracterização climática do estado de Minas Gerais. Informe Agropecuário - Belo Horizonte 12(138): 9-13.

APG II. 2003. An update of the Angiosperm Phylogeny Group classification for the orders and families of flowering plants: APG II. Botanical Journal of the Linnean Society 14: 399-436. 
Bortoluzzi, R.L.C.; Carvalho-Okano, R.M.; Garcia, F.C.P. \& Tozzi, A.M.G.A. 2004. Leguminosae, Papilionoideae no Parque Estadual do Rio Doce, Minas Gerais, Brasil. II: árvores e arbustos escandentes. Acta Botanica Brasilica 18(1): 49-71.

Botrel, R.T.; Oliveira-Filho, A.T.; Rodrigues, L.A. \& Curi, N. 2002. Influência do solo e topografia sobre as variações da composição florística e estrutura da comunidade arbóreaarbustiva de uma floresta estacional semidecidual em Ingaí, MG. Revista Brasileira de Botânica 25(2): 195-213.

Bovini, M.G; Carvalho-Okano, R.M. \& Vieira, M.F. 2001. Malvaceae A. Juss. no Parque Estadual do Rio Doce, Minas Gerais, Brasil. Rodriguésia 52(81): 17-47.

Buckman, H.O. \& Brady, N.C. 1968. Natureza e propriedades dos Solos. 2a. ed. Compêndio Universitário sobre Edafologia, Rio de Janeiro.

Cardoso, E. \& Schiavini, I. 2002. Relação entre distribuição de espécies arbóreas e topografia emum gradiente florestal na Estação Ecológica do Panga (Uberlândia, MG). Revista Brasileira de Botânica 25(3): 277-289.

Carvalho, D.A.; Oliveira-Filho, A.T.; Vilela, E.A. \& Gavilanes, M. L. 1995. Estrutura fitossociológica de mata ripária do alto Rio Grande (Bom Sucesso, estado de Minas Gerais). Revista Brasileira de Botânica 18(1): 39-49.

CEMIG - Companhia Energética de Minas Gerais. 2004. Estação Ecológica de Proteção e Desenvolvimento Ambiental de Peti (online).Belo Horizonte: CEMIG. http:// www.cemig.com.br/meio_ambiente/ reserv_peti.asp. Acessado em 31 de agosto de 2004.

CETEC - Fundação Centro Tecnológico de Minas Gerais. 1989. Composição florística e tipos vegetacionais da Estação de Proteção e Desenvolvimento Ambiental de Peti/CEMIG, MG. SAT/CETEC, Belo Horizonte. 42p.

Cottam, G. \& Curtis, J.T. 1956. The use of distance measures in phytosociological sampling. Ecology 37: 451-460.
EMBRAPA - Empresa Brasileira de Pesquisa Agropecuária. 1999. Sistema brasileiro de classificação de solos. Cap. 1: Atributos Diagnósticos. Centro Nacional de Pesquisa de Solos. 412p.

Espírito-Santo, F.D.B.; Oliveira-Filho, A.T.; Machado, E.L.M.; Souza, J.S.; Fontes, M.A.L. \& Marques, J.J.G.S.M. 2002. Variáveis ambientais e a distribuição de espécies arbóreas em um remanescente de floresta estacional semidecídua montana no campus da Universidade Federal de Lavras, MG. Acta Botanica Brasilica 16: 331-356.

Fonseca, G.A.B. 1985. The vanishing Brazilian Atlantic Forest. Biological Conservation, London 34 (1): 17-34.

Fonseca, G.A.B. 1997. Impactos antrópicos e biodiversidade terrestre. In: Paula, J.A. (coord.). Biodiversidade, população e economia em uma região de mata atlântica. Belo Horizonte: Roana: PADCT/CIAMBI/ UFMG/CEDEPLAR_ECMVS. 672p.

Gentry, A.H. 1995. Patterns of diversity and floristic composition in neotropical montane forests. In: Churchill, S.P.; Balslev, H.; Forero, E. \& Luteyn, J.L. (eds.). Biodiversity and conservation of neotropical montane forests. Neotropical montane forest biodiversity and conservation Symposium 1. New York Botanical Garden, New York. Pp. 103-126.

Giraldo-Cañas, D. 2000. Variación de la diversidad florística en un mosaico sucesional en la Cordillera Central Andina (Antioquia, Colombia). Darwiniana 38(1-2): 33-42.

Gonçalves, M. \& Lombardi, J.A. 2004. Adições ao conhecimento da composição florística de dois remanescentes de Mata Atlântica do sudeste de Minas Gerais, Brasil. Lundiana 5(1):3-8.

Gotelli, N.J. \& Colwell, R.K. 2001. Quantifying biodiversity: procedures and pitfalls in the measuring and comparison of species richness. Ecology Letters 4: 379-391.

Gotelli, N.J. \& Entsminger, G.L. 2003. EcoSim: Null models software for ecology. Acquired Intellig. Inc. Kesey-Bear. <http://homepages. 
together.net/ gentsmin/ecosim.htm>. Acesso em 18 setembro 2005.

Greig-Smith, P. 1983. Quantitative plant ecology. 3th ed. Blackwell, Oxford. 485p.

Harper, J.L. 1977. Population biology of plants. London. 892p.

Hartshorn, G.S. 1989. Application of gap theory to tropical forest management: natural regeneration on strip clear cuts in the Peruvian Amazon. Ecology 70(3): 567-569.

IBAMA. 2008. Instituto Brasileiro de Meio Ambiente e Recursos Naturais Renováveis. Instrução Normativa n ${ }^{\circ}$ 06, 23/09/2008.

IBGE. 1993. Instituto Brasileiro de Geografia e Estatística. Mapa de vegetação do Brasil. IBGE, Rio de Janeiro.

Ivanauskas, N.M.; Rodrigues, R.R. \& Nave, A. G. 1999. Fitossociologia de um trecho de floresta estacional semidecidual em Itatinga, São Paulo, Brasil. Scientia Forestalis 56: 83-99.

Leitão-Filho, H.F. 1982. Aspectos taxonômicos das florestas do estado de São Paulo. Anais do Congresso Nacional sobre Essências Nativas Silviculturais, São Paulo 16: 197-206.

Leitão-Filho, H.F. 1992. A Flora arbórea da Serra do Japi. In: Morellato, L.P.C. (ed.). História Natural da Serra do Japi - Ecologia e Preservação de uma Área Florestal do Sudeste do Brasil. Campinas, Editora da UNICAMP. Pp. 40-62.

Lombardi, J.A. \& Gonçalves, M. 2000. Composição florística de dois remanescentes de Mata Atlântica do sudeste de Minas Gerais, Brasil. Revista Brasileira de Botânica 23(3): 255-282.

Lopes, W.P.; de Paula, A.; Sevilha, A.C. \& Silva, A.F. 2002a. Composição da flora arbórea de um trecho de floresta estacional no jardim botânico da Universidade Federal de Viçosa (face sudoeste), Viçosa, Minas Gerais. Revista Árvore 26(3): 339-347.

Lopes, W.P.; Silva, A.F.; Souza, A.L. \& Meira-Neto, J.A.A. 2002b. Estrutura fitossociológica de um trecho de vegetação arbórea no Parque Estadual do Rio Doce
- Minas Gerais, Brasil. Acta Botanica Brasilica 16(4): 443-456.

MacArthur, R.H. \& Wilson, E.O. 1967. The theory of island biogeography. Princeton University Press, Princeton. 203p.

Marangon, L.C.; Soares, J.J. \& Feliciano, L.P. 2003. Florística arbórea da Mata da Pedreira, município de Viçosa, Minas Gerais. Revista Árvore 27(2): 207-215.

Martins, F.R. 1991. Estrutura de uma floresta mesófila. Editora da UNICAMP, Campinas. 246p.

McCune, B. \& Mefford, M.J. 1999. PC-ORD. Version 4.14. Multivariate analysis of ecological data. MjM Software, Glaneden Beach.

Meira-Neto, J.A.A. \& Martins, F.R. 2000. Composição florística do estrato herbáceo-arbustivo de uma floresta estacional semidecidual em Viçosa - MG. Revista Árvore 24(4): 407-416.

Meyer, S.T.; Silva, A.F.; Marco Jr., P. \& Meira Neto, J.A.A. 2004. Composição florística da vegetação arbórea de um trecho de floresta de galeria do Parque Estadual do Rola Moça na Região Metropolitana de Belo Horizonte, MG, Brasil. Acta Botanica Brasilica 18(4): 701-709.

Müeller-Dombois, D. \& Ellenberg, H. 1974. Aims and methods of vegetation ecology. Wiley and Sons, New York. 547p.

Myers, N.; Mittermeier, R.A.; Mittermeier, C.G.; Fonseca, G.A.B. \& Kent, J. 2000. Biodiversity hotspots for conservation priorities. Nature 403: 853-858.

Nunes, Y.R.F. \& Pedralli, G. 1995. Desenvolvimento de metodologia para adensamento e recomposição da vegetação na EPDA-Peti, MG. Bios 2(3): 53-61.

Oliveira-Filho, A.T. \& Fontes, M.A.L. 2000. Patterns of floristic differentiation among Atlantic forests in south-eastern Brazil, and the influence of climate. Biotropica 32(4): 793-810.

Oliveira-Filho, A.T. 1989. Composição florística e estrutura comunitária da floresta de galeria 
do córrego da Paciência, Cuiabá, (MT). Acta Botanica Brasilica 3(1): 91-112.

Oliveira-Filho, A.T.; Scolforo, J.R. \& Mello, J.M. 1994a. Composição florística e estrutura comunitária de um remanescente de floresta semidecídua montana em Lavras (MG). Revista Brasileira de Botânica 17(2): 159-174.

Oliveira-Filho, A.T.; Vilela, E.A.; Carvalho, D.A. \& Gavilanes, M.L. 1994b. Effects of soils and topography on the distribution of tree species in a tropical riverine forest in south-eastern Brazil. Journal of Tropical Ecology 10(4): 483-508.

Pagano, S.N. \& Leitão-Filho, H.F. 1987. Composição florística do estrato arbóreo de mata mesófila semidecídua, no município de Rio Claro (estado de São Paulo). Revista Brasileira de Botânica 10: 37-47.

de Paula, A.; Silva, A.F.; Marco Júnior, P.; Santos, F.A.M. \& Souza, A.L. 2004. Sucessão ecológica da vegetação arbórea em uma Floresta Estacional Semidecidual, Viçosa, MG, Brasil. Acta Botanica Brasilica 18(3): 407-423.

Pedralli, G. \& Teixeira, M.C.B. 1997. Levantamento florístico e principais fisionomias na Estação de Pesquisa e Desenvolvimento Ambiental de Peti, Santa Bárbara, MG, Brasil. Iheringia, Série Botânica 48: 15-40.

Pielou, E.C. 1966. The measurement of diversity in different types of biological collections. Journal of Theoretical Biology 13: 131-144.

Richards, P.W. 1975. The Tropical Rain Forest: an ecological study. Cambridge University Press. 450p.

Rizzini, C. T. 1979. Tratado de fitogeografia do Brasil. Vol.2. Hucitec/EDUSP, São Paulo. $374 p$.

Rocha, C.T.V.; Carvalho, D.A.; Fontes, M.A.L.; Oliveira-Filho, A.T.; Van den Berg, E. \& Marques, J.J.G.S.M. 2005. Comunidade arbórea de um continuum entre floresta paludosa e de encosta em Coqueiral, Minas Gerais, Brasil. Revista Brasileira de Botânica 28(2): 203-218.
Rodrigues, M.A.C.M.; Miranda, I. S. \& Kato, M.S.A. 2007. Estrutura de florestas secundárias após dois diferentes sistemas agrícolas no nordeste do estado do Pará, Amazônia Oriental. Acta Amazônica 37(4): 591-598.

Rodrigues, R.R. 1989. Análise estrutural das formações florestais ripárias. In: Barbosa, L.M. (coord.) Simpósio sobre mata ciliar. Anais do Simpósio sobre Mata Ciliar. Campinas, Fundação Cargil: 99-119.

Rodrigues, R.R.; Morellato, L.P.C.; Joly, C.A. \& Leitão-Filho, H.F. 1989. Estudo florístico e fitossociológico em um gradiente altitudinal de mata estacional mesófila semidecídua, na Serra do Japi, Jundiaí, SP. Revista Brasileira de Botânica 12: 71-84.

Salisbury, F.B. \& Ross, C.W. 1992. Plant physiology. $5^{\mathrm{a}}$ ed. Wadsworth Publ. 682p.

Scolforo, J.R.S.; Pulz, F.A. \& Mello, J.M. 1998. Modelagem da produção, idade da floresta nativa, distribuição espacial das espécies e a análise estrutural. In: Scolforo, J. R. S. Manejo florestal. Lavras: UFLA/FAEPE: 189-245.

Shepherd, G.J. 1991. Fitopac - Manual do usuário. UNICAMP, Departamento de Botânica, Campinas. 93p.

Silva, A.F. \& Leitão-Filho, H.F.1982. Composição florística e estrutura de um trecho de Mata Atlântica de encosta do município de Ubatuba (São Paulo, Brasil). Revista Brasileira de Botânica 5(1-2): 43-52.

Silva, L.F. 1996. Solos tropicais: Aspectos pedológicos, ecológicos e de manejo. Terra Brasilis, São Paulo. 137p.

Somner, G.V. \& Ferrucci, M.S. 2004. A new species of Cupania sect. Trigonocarpus (Sapindaceae) from Brazil. Botanical Journal of the Linnean Society 146: 217-221.

Souza, J.S.; Espírito-Santo, F.D.B.; Fontes, M.A.L.; Oliveira-Filho, A.T. \& Botezelli, L. 2003. Análise das variações florísticas e estruturais da comunidade arbórea de um fragmento de floresta semidecídua às margens do rio Capivari, Lavras-MG. Revista Árvore 27(2): 185-206. 
Sposito, T.C. \& Stehmann, J.R. 2006. Heterogeneidade florística e estrutural de remanescentes florestais da Área de Proteção Ambiental ao sul da região metropolitana de Belo Horizonte (APA Sul-RMBH), Minas Gerais. Acta Botanica Brasilica 20(2): 347-362.

Strauch, N. 1955. A bacia do Rio Doce. IBGE, Rio de Janeiro. 172p.

Tabarelli, M. \& Mantovani, W. 1999. A regeneração de uma floresta tropical montana após corte e queima (São PauloBrasil). Revista Brasileira de Biologia 59(2): 239-250.

Ter Braak, C.J.F. 1987. The analysis of vegetation environment relationship by canonical correspondence analysis. Vegetatio 69: 69-77.

Thomaz, L.D. \& Monteiro, R. 1997. Composição florística da Mata Atlântica de Encosta da Estação Biológica de Santa Lúcia, município de Sana Tereza-ES. Boletim do Museu de Biologia Mello Leitão 7: 3-43.

Torres, R.B.; Martins, F.R. \& KinoshitaGouvea, L.S. 1997. Climate, soil and tree flora relationships in forests in the state of São Paulo, southeastern Brazil. Revista Brasileira de Botânica 20(1): 41-49.

Uhl, C.; Clark, K.; Dezzeo, N. \& Maquirino, P. 1988. Vegetation dynamics in Amazonian treefall gaps. Ecology 69(3): 751-763.

Veloso, H.P. 1966. Atlas florestal do Brasil. Ministério da Agricultura, Riode Janeiro. 82p.

Veloso, H.P.; Rangel-Filho, A.L.R. \& Lima, J.C.A. 1991. Classificação da vegetação brasileira adaptada a um sistema universal. Rio de Janeiro. 123p.

Whitmore, T.C. 1990. An introduction to tropical rain forests. Clarendon Press, Oxford. 226p.

Zar, J.H. 1999. Biostatistical analysis. Prentice-Hall, New Jersey. 662p. 